\title{
Validation of Puck's failure criterion for CFRP composites in the cryogenic regime
}

\author{
Jörg Hohe ${ }^{1} \oplus \cdot$ Michael Schober $^{1} \cdot$ Klaus-Peter Weiss $^{2} \cdot$ Simon $^{\text {Appel }}{ }^{3}$
}

Received: 29 June 2020 / Revised: 2 September 2020 / Accepted: 2 September 2020 / Published online: 11 September 2020

(c) The Author(s) 2020

\begin{abstract}
For future launch vehicles, lightweight cryogenic pressure vessels are required for storage of the liquid hydrogen fuel. For their structural assessment, reliable and validated failure criteria are required. The present contribution provides an overview over the results of an ongoing research activity concerned with the validation of Puck's composite failure criterion in the cryogenic regime. In a first step, an experimental investigation on unidirectionally fiber reinforced materials on coupon level has been performed. This test campaign has been complemented by tests on small breadboard-type specimens with an angle-ply stacking sequence. The specimens were featuring holes and tapered sections to provide stress gradients and concentrations. Test were performed at ambient temperature and in a liquid Helium environment. Puck's failure criterion has been applied and found to provide a good prediction of first ply failure in both environments.
\end{abstract}

Keywords Composites $\cdot$ Mechanical testing $\cdot$ Analysis $\cdot$ Prediction and virtual testing $\cdot$ Damage tolerance

\section{Introduction}

For next generation launch vehicles, safe and reliable fuel vessels are required. For the storage of liquid hydrogen and oxygen, the respective vessels have to be able to withstand temperatures in the cryogenic regime down to $20 \mathrm{~K}$. For their design, the use of carbon fiber reinforced plastics (CFRP) is mandatory for reasons of lightweight construction. Further to their low specific weight, the use of CFRP materials circumvents the problem of the embrittlement of most metals in the cryogenic temperature range. The safe design of CFRP pressure vessels requires the availability of validated failure criteria in all relevant temperature ranges. In literature, a variety of failure criteria for fiber reinforced plastics (FRP) such as the well-known Tsai-Wu criterion [19], the Hashin criterion [4, 5], the Puck criterion [16, 17]

Jörg Hohe

joerg.hohe@iwm.fraunhofer.de

1 Fraunhofer Institute for Mechanics of Materials IWM, Wöhlerstr. 11, 79108 Freiburg, Germany

2 Karlsruhe Institute of Technology-KIT, Institute for Technical Physics (ITEP), Hermann-von-Helmholtz-Platz 1, 76344 Eggenstein-Leopoldshafen, Germany

3 ATG-Europe for the European Space Agency, Postbus 299, 2200 AG Noordwijk, The Netherlands or the LaRC criteria (Dávila et al. [3], Pinho et al. [15]) and others are well established. Nevertheless, their capability at cryogenic temperatures close to the absolute zero has not been studied in a consecutive manner.

In the cryogenic range, specific problems arise such as thermally induced residual stresses between fibers and matrix as well as between adjacent plies. The residual stresses may play a key role in damage and failure of composites in this temperature range, since they contribute to the overall stresses in addition to the stresses induced by the external loads. In several contributions, the thermally induced stresses alone are suspected to cause matrix cracking (Lord and Dutta [13], Hyer et al. [11]). On the other hand, the strength of the polymeric matrix of fiber reinforced composites increases significantly, if the temperature approaches the absolute zero (Hui and Dutta [10]). Hence, opposing effects on the strength of CFRP laminates are active, when cooled down into the cryogenic thermal regime. For this reason, no clear, monotonic tendency of the temperature effect on the macroscopic strength of CFRP laminates has been observed (Kumgai and Shindo [12]). Furthermore, the cooling rate may have significant effects. Meng et al. [14] found that slow cooling rates down to $77 \mathrm{~K}$ do not cause microcracking, whereas higher cooling rates may do. Regarding the integrity assessment, classical criteria based approaches or continuum damage mechanics type 
approaches may be used. In the latter sense, Shokrieh et al. [18] provided a Hashin [5] based progressive failure model for glass fiber reinforced materials down to $213 \mathrm{~K}$.

The present contribution is concerned with an assessment of Puck's composite failure criterion $[16,17]$ in the temperature range from ambient temperature $(296 \mathrm{~K})$ down to the cryogenic range at $4 \mathrm{~K}$. It thereby provides an overview of the results obtained in the context of a broader and ongoing research activity (Hohe et al. [7]). In a first step, an experimental study was performed on coupon level. The material was a unidirectionally carbon fiber reinforced epoxy matrix composite. The test matrix comprised of tensile, compressive and shear experiments within and perpendicular to the fiber direction. The experiments were performed at ambient temperature $(296 \mathrm{~K})$ as well as in the cryogenic range at $4 \mathrm{~K}$ using a liquid Helium environment. In a second step, the experiments on coupon level were complemented by an experimental program on breadboard-type specimens with a more complex geometry. The specimens were supplied with holes and/or tapered sections to induce more complex local stress states as well as stress gradients. The demonstrator specimens were manufactured from angle-ply laminates.

The experimental data base has been utilized to assess and to validate Puck's criterion throughout the considered temperature range. Its failure envelope was determined from the experimental data base on coupon level. Subsequently, the criterion was applied to the demonstrator tests. Considering the experimental and numerical results, Puck's criterion $[16,17]$ has been found to adequately describe first ply failure of the laminates considered, provided that a more general definition of the slope of the failure envelope around pure shear stress states is employed. Both, the position of first ply failure and the corresponding load level were predicted accurately. Regarding the complete failure of the laminates, conservative results were obtained.

\section{Experimental investigation on coupon level}

\subsection{Materials and methods}

As a model material, a unidirectionally carbon fiber reinforced epoxy matrix material has been selected as a relevant material example for spacecraft applications. The material system comprised of intermediate modulus, high strength fibers (HexTow IM7). The matrix consisted of HexPly 8552 epoxy with a curing temperature in the range of $110^{\circ}-180^{\circ} \mathrm{C}$ according to the supplier's specification. Plane plates were manufactured by an autoclave process. From the plane plates, the specimens were manufactured using water jet cutting.
Within the context of a larger investigation (Hohe et al. [7]), the material was characterized in tensile, compressive and shear experiments. Tests were performed within and perpendicular to the fiber direction. In addition, off-axis experiments under different angles were performed. Due to the limited space within the cryostat for cryogenic testing, non-standard test specimens had to be employed. The tensile experiments within the fiber direction were performed on straight specimens with a cross section of $1 \times 8 \mathrm{~mm}$. For the tensile experiments perpendicular to the fiber direction as well as for the off-axis tensile tests, dog-bone specimens with a cross section of $3 \times 8 \mathrm{~mm}$ were employed. All compressive experiments were based on cuboid specimens, also with a cross section of $3 \times 8 \mathrm{~mm}$. For the shear experiments, double slitted tensile specimens with $3 \mathrm{~mm}$ thickness and a shear length of $11 \mathrm{~mm}$ were employed (Hohe et al. $[6,7])$. Advantage of the employed compression and shear specimens is that no massive test rig for guidance of the specimens such as a Celanese or Iosipescu device was necessary. By this means, problems with thermally induced distortion and subsequent sticking or friction of the test rig were avoided.

All specimens were tested till failure under quasi-static loading conditions under prescribed cross-head displacement. During the experiments, the cross-head displacement and the resulting force were recorded continuously. The tensile strains were determined by direct extensometer measurement on the specimen surfaces. For the compression tests, similar measurements were performed with the extensometer blades on the surfaces of the loading device. The experiments were performed in one to three repetitions.

At ambient temperature, the experiments were performed in an electromechanical H\&P testing machine using standard test rigs for the respective loading situation. The experiments were performed in a laboratory air environment at approximately $296 \mathrm{~K}$. At cryogenic temperature, the experiments were performed in a liquid Helium environment at a temperature of $4.2 \mathrm{~K}$. A MTS hydraulic testing machine equipped with a cryostat has been employed. The tests were evaluated by means of the standard procedures for the respective loading situations.

\subsection{Results}

The results of the individual experiments were evaluated with respect to the strength limits in the fiber oriented coordinate system with the $x_{1}$-direction being the fiber direction. The experiments within and perpendicular to the fiber direction directly resulted in uniaxial strength limits $R_{11}^{\mathrm{t}}$, $R_{11}^{\mathrm{c}}, R_{22}^{\mathrm{t}}, R_{22}^{\mathrm{c}}$ and $R_{12}^{\mathrm{s}}$, respectively. Combined failure load points were obtained in the off-axis experiments, involving both inter fiber tension or compression and shear as well as small amounts of longitudinal fiber tension or compression. 
The obtained strength limits are presented in Table 1 . The results reveal that by the decrease of the temperature from ambient temperature down to $4 \mathrm{~K}$, the tensile and compressive strengths $R_{22}^{\mathrm{t}}$ and $R_{22}^{\mathrm{c}}$ perpendicular to the fiber direction increase by $22 \%$ and $70 \%$, respectively. The shear strength $R_{12}^{\mathrm{s}}$ decreases by $10 \%$, whereas the compressive strength $R_{11}^{\mathrm{c}}$ within the fiber direction increases slightly by $9 \%$. For the tensile strength $R_{11}^{\mathrm{t}}$ with the fiber direction, no valid results were obtained at cryogenic temperature so that no quantification of the cryogenic thermal effect is possible.

Among the failure criteria available in literature, Puck's criterion had been identified as the most suitable one for both temperature ranges in a previous contribution (Hohe et al. [6]). Therefore, this criterion is employed here. The results

Table 1 Material parameters

\begin{tabular}{|c|c|c|c|c|c|}
\hline $\begin{array}{l}\mathrm{T} \\
{[\mathrm{K}]}\end{array}$ & $\begin{array}{l}R_{11}^{\mathrm{t}} \\
{[\mathrm{MPa}]}\end{array}$ & $\begin{array}{l}R_{11}^{\mathrm{c}} \\
{[\mathrm{MPa}]}\end{array}$ & $\begin{array}{l}R_{22}^{\mathrm{t}} \\
{[\mathrm{MPa}]}\end{array}$ & $\begin{array}{l}R_{22}^{\mathrm{c}} \\
{[\mathrm{MPa}]}\end{array}$ & $\begin{array}{l}R_{12}^{\mathrm{s}} \\
{[\mathrm{MPa}]}\end{array}$ \\
\hline 296 & 2747 & 773 & 50 & 228 & 46 \\
\hline 4 & $(1260)^{*}$ & 846 & 62 & 388 & 41 \\
\hline
\end{tabular}

*Lower bound value
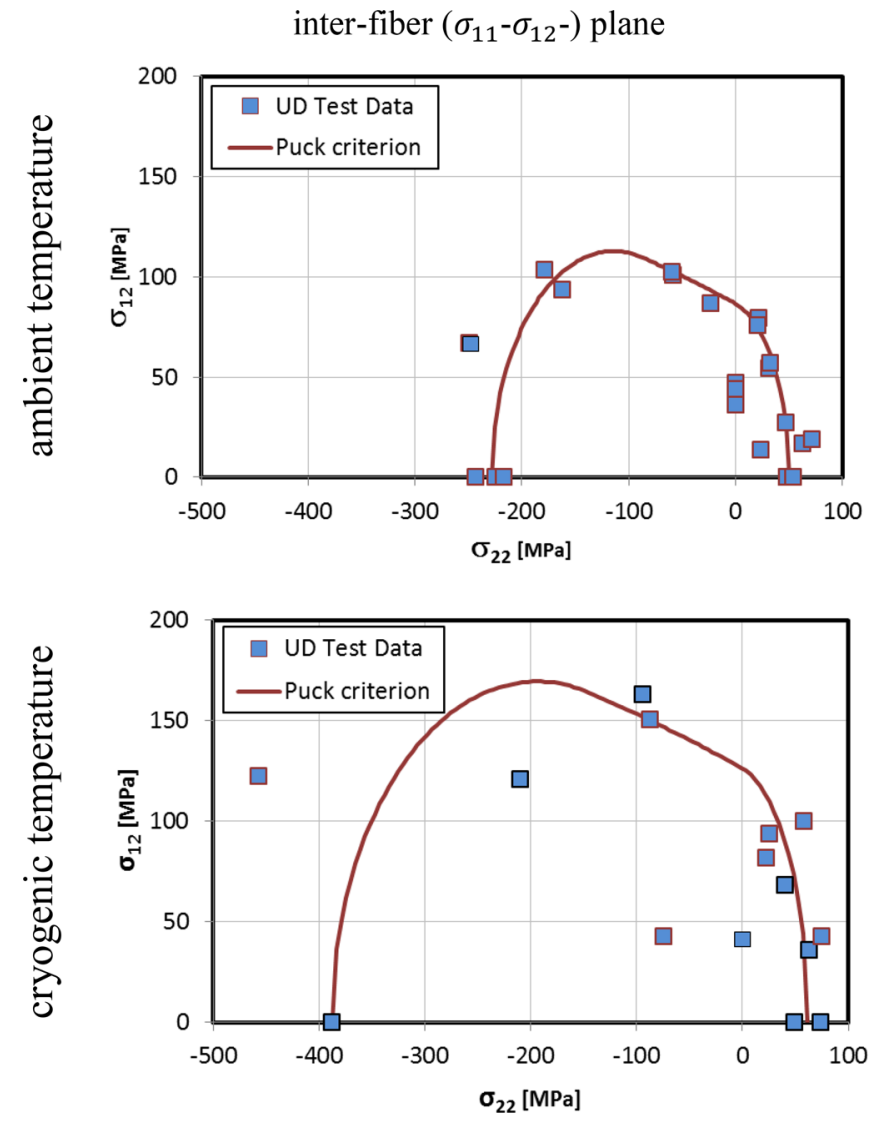

are presented in Fig. 1. Experimental results are denoted by symbols. Filled symbols are related to valid material failure, whereas open symbols denote maximum stress data, where specimens did not fail or did not fail in valid modes, thus providing lower bound values for the real failure loads. Solid lines denote the predictions by the Puck failure envelope. Where no valid data were obtained, the failure envelope is represented open at the respective side. The failure envelopes are constructed from the normal strengths $R_{11}^{\mathrm{t}}, R_{11}^{\mathrm{c}}$, $R_{22}^{\mathrm{t}}, R_{22}^{\mathrm{c}}$, in tension and compression, respectively, as well as the shear strength $R_{12}^{\mathrm{s}}$. The results obtained in the offaxis tensile and compressive experiments on unidirectionally fiber reinforced material-transformed back into the fiber related coordinate system - are presented in a projection into the $\sigma_{22}-\sigma_{12}$-plane. They were employed for determination of the shape parameters $p_{12}^{(+)}=p_{12}^{(-)}$of the Puck failure envelope determines as 0.3 and 0.4 for ambient and cryogenic temperature, respectively. In the tensile experiments within the fiber direction at cryogenic temperature, no valid strength values were obtained (open symbols). Due to a thermally induced loss in clamping pressure, slip of the specimens in the clamping system could not be avoided here. Thus, the
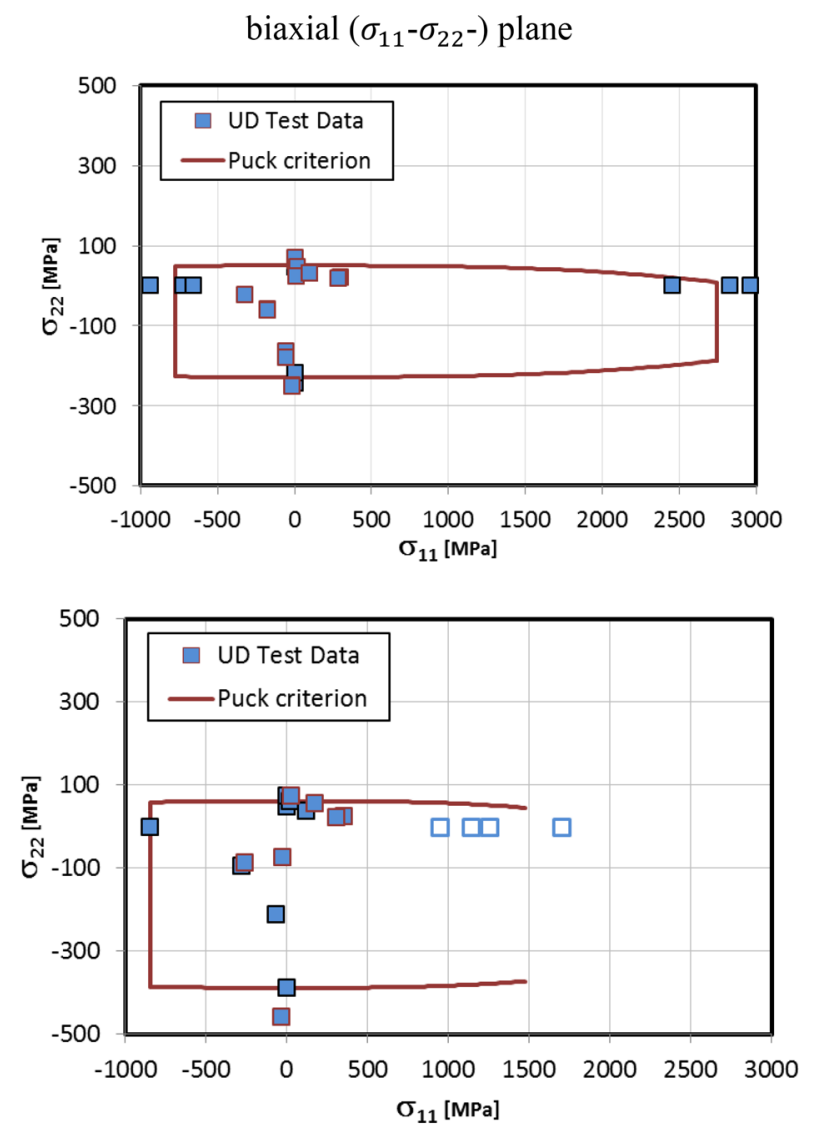

Fig. 1 Experimental results on coupon level and failure envelopes 
maximum stresses obtained therein provide lower bounds on the respective strength.

Puck's failure envelope $[16,17]$ is found to provide a good approximation of the experimental data for both temperatures concerning both, the inter fiber $\left(\sigma_{11^{-}} \sigma_{12^{-}}\right)$and the biaxial $\left(\sigma_{11^{-}} \sigma_{22^{-}}\right)$plane in stress space. Some data points which appear to be located inside the failure envelope in the biaxial load $\left(\sigma_{11^{-}} \sigma_{22^{-}}\right)$plane (right column of subfigures in Fig. 1) are in fact located above the biaxial plane, i.e., are associated with a non-zero shear stress $\sigma_{12}$ and thus do not violate the prediction of the criterion. Nevertheless, it has to be mentioned that especially at cryogenic temperature, a distinct scatter of the results has been obtained.

Concerning the temperature ranges considered (ambient conditions in the top row of subfigures, cryogenic conditions in the bottom row of subfigures in Fig. 1), it appears that the strength of the material in general increases with decreasing temperature. Especially in the inter fiber $\left(\sigma_{11^{-}} \sigma_{12^{-}}\right)$plane in stress space, significant increases in strength are observed when the temperature is decreased from ambient temperature down to $4.2 \mathrm{~K}$. In the inter fiber plane, the macroscopic material strength is predominantly governed by the strength of the polymeric matrix. Since the strength of most polymers increases with decreasing temperature-especially in the cryogenic range - an increased strength of the composite material is observed. Obviously, the strength increase of the matrix exceeds possible effects due to the severe mismatch in the coefficients of thermal expansion for fibers and matrix. Notice that the failure envelope in the inter fiber $\left(\sigma_{11^{-}} \sigma_{12^{-}}\right)$ plane does not scale in a self-similar manner, when the temperature is decreased from ambient temperature to the liquid Helium temperature.

Under longitudinal compression within the fiber $\left(\sigma_{11^{-}}\right)$ direction, only minor effects are observed. For longitudinal tensile stresses, no general judgement is possible, since no valid strength limits could have been determined in the cryogenic regime due to slip of the specimens in the clamping system (see Sect. 2.1). Full details on the experimental results on coupon level can be found in the technical report on the project (Hohe et al. [7]).

\section{Demonstrator tests}

\subsection{Materials and methods}

To provide experimental data under more complex loads, including multi-axial stress states and distinct stress gradients, small breadboard type specimens were employed. The specimens were designed such that they were suitable for both the ambient temperature and the cryostat test rigs. All specimens had the same external geometry of a $200 \mathrm{~mm}$ long and $30 \mathrm{~mm}$ wide rectangular strip. The strips were supplied either with central holes or with symmetric tapered sections as geometric features inducing the mentioned more general stress and strain states when loaded. In addition, specimens combining both features were manufactured. The geometry of the demonstrators is presented in Fig. 2. All demonstrator test specimens were manufactured from a $\left[ \pm 30^{\circ}\right]$ angle ply laminate, using the same base material as in the experiments on coupon level (see Sect. 2.1.)

The specimens were tested under axial tension till failure. During the tests, the local strains at selected positions were measured to be able to detect local failure events even in the cryogenic experiments, where no direct observation of the test was possible due to the test setup being encapsulated in the cryostat chamber. As strain measurement points, the notch roots of the tapered sections as well as the position directly beside the holes were chosen, since these positions are the positions, where stress concentrations are to be expected. On breadboard specimens without the respective features, a strain measurement at similar positions was performed to provide data for comparison. In the tests at ambient temperature, resistance strain gauges were used. The strain gauges were adhesively applied to the front surface of the specimen. From the rear surface of the specimens, the experiments were video recorded to be able to identify local failure events. In the experiments at cryogenic temperature, the local strains were determined by a tactile system using clip-on extensometers. The extensometers were applied to
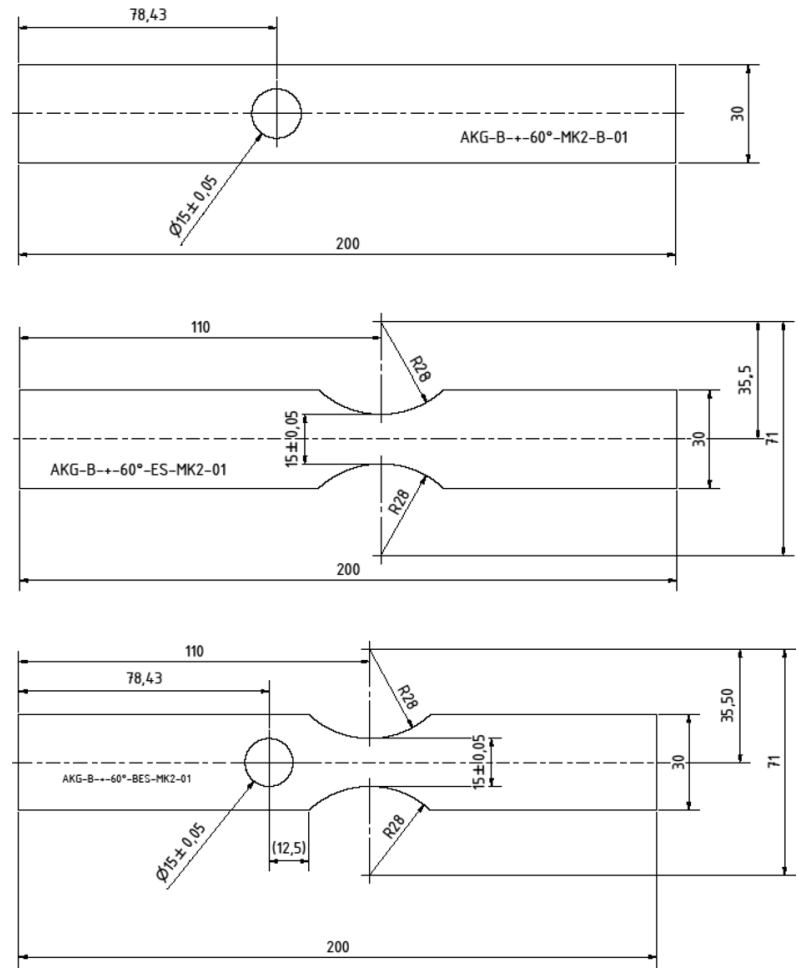

Fig. 2 Breadboard specimen geometries 
both, the front and the rear surfaces of the specimens. The measurement positions were the same as in the experiments at ambient temperature.

At both temperatures, the specimens were tested till failure in a tensile mode under quasi-static loading conditions. During the experiments, the local strains at the selected positions together with the cross-head displacement and the resulting force were recorded continuously.

To be able to assess the local loading conditions, all experiments were simulated numerically using the finite element method (ABAQUS [1]). For this purpose, finite element models consisting of standard displacement based 4-node shell/plate elements with bi-linear displacement and rotation interpolation were used. The material was defined as a layered material according to the stacking sequence of the breadboard specimens. Throughout the analyses, a linear elastic material model without damage and failure assumptions was employed. Although-except for setting effects-no distinct non-linearity was observed in the experiments, the analyses were performed within the geometrically non-linear framework. No further higher-order effects such as free-edge effects were considered. As in the real experiments, the finite element model were loaded in a displacement controlled mode. For this purpose, prescribed displacements were applied to one of the specimen ends, whereas the opposite end was fixed in the longitudinal direction. From the results, the stresses along the boundaries at the features, i.e., the stresses in the critical zones according to the observed failure modes were extracted and transformed into the local fiber oriented coordinate system for each ply. Subsequently, the stresses were used for an integrity assessment by Puck's criterion $[16,17]$ using the failure envelopes presented in Fig. 1. The evaluation paths for the integrity assessment are sketched in Fig. 3. Only one side of the specimen was considered in the evaluation.

\subsection{Results}

The breadboard specimens were tested under displacement control till fracture. During the loading history, multiple local failure events were observed prior to complete failure. At ambient temperature, the instants of the local failure events were identified from the video recordings of the

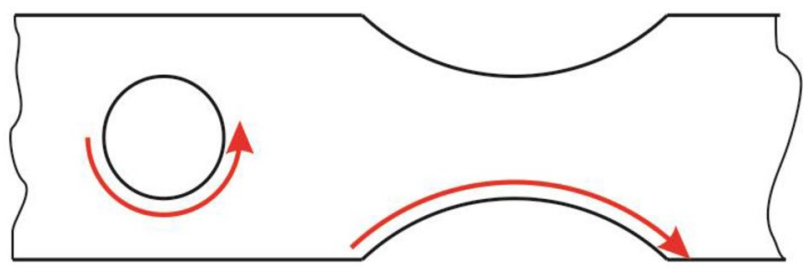

Fig. 3 Stress evaluation paths experiments. In the cryogenic regime, no video recordings were available so that the instants of the local failure events had to be identified from discontinuities in the local strain recordings. Figure 4 shows a typical force vs. cross head displacement record with red diamond markings at the instants of identified local failure events (specimen with both, hole and tapered section tested at ambient temperature). The initial progressive non-linear response is related to setting effects in the load train of the test rig. First ply failure occurs at a crosshead displacement of approximately $3.4 \mathrm{~mm}$ or an applied force of approximately $7 \mathrm{kN}$. In most cases, the local failure events consisted in the localized development of contained inter fiber cracks emanating from the "features" and/ or the development of local delaminations in these areas, usually between the top or bottom plies and their respective neighbors.

Final failure in all cases was initiated at the "features", i.e., at the holes or in the root of the tapered sections. Typical failure modes for the three breadboard specimen types are presented in Fig. 5a-c. For all geometries, the final failure modes are predominantly inter fiber failure modes. The inter fiber failures on ply level go along with significant amounts of delamination between adjacent plies. Since the specimens consisted of multidirectional laminates, i.e., $\left[ \pm 30^{\circ}\right]$ angle ply laminates, inter fiber failure can only lead to a complete separation of the specimen, if the interfaces between two failed plies with different fiber orientation become delaminated. The delaminations become obvious in the side view of one of the "hole" demonstrators presented in Fig. 5d.

At the instant of the first ply failure event as either observed visually or detected from the local strain measurements, the stresses along the features were determined from the results of the finite element simulation of the respective experiments. In this context, finite element analysis and experiment were correlated in terms of the resulting force, i.e., similar states were assumed if the applied force in the

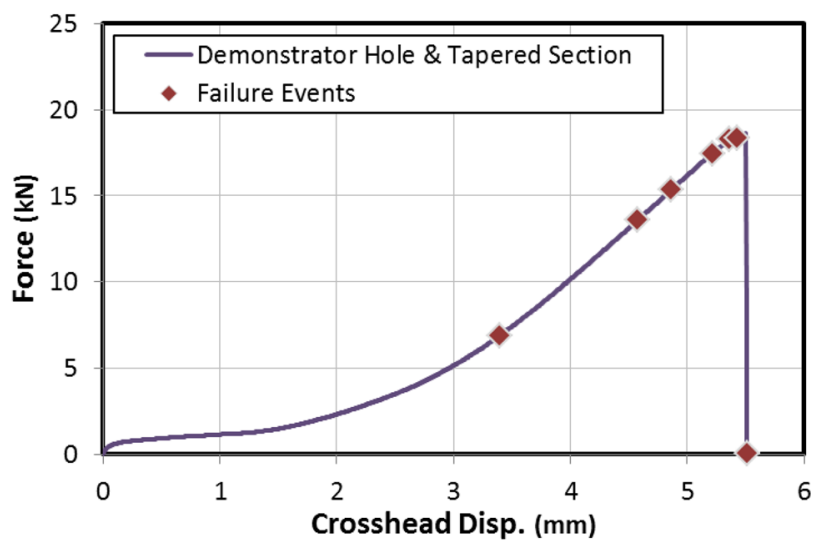

Fig. 4 Selected force-displacement record (specimen with hole and tapered section) 


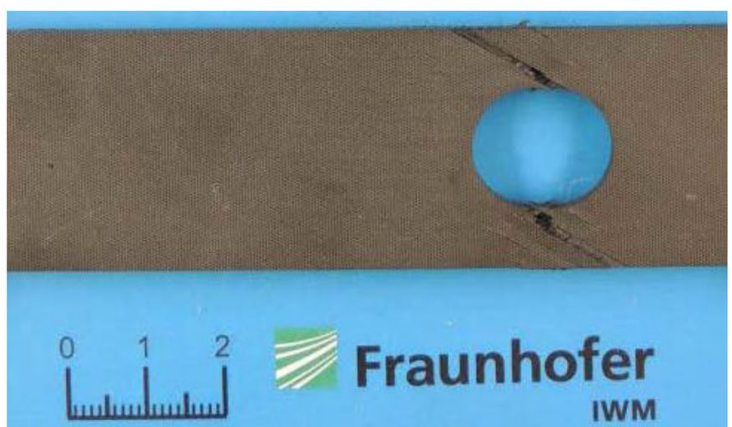

(a) specimen featuring hole only

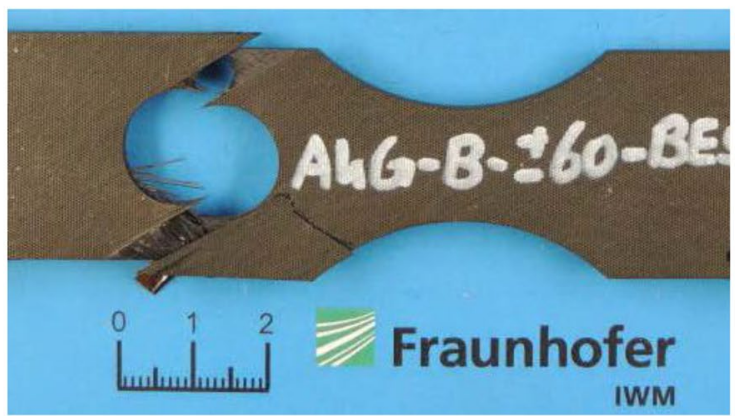

(c) specimen featuring both hole and tapered section

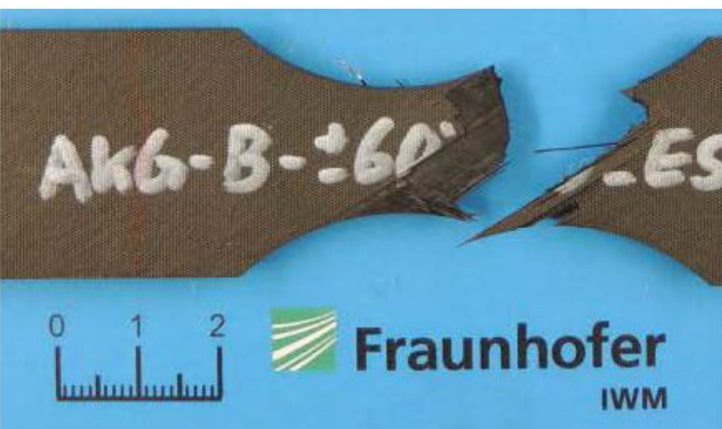

(b) specimen featuring tapered section only

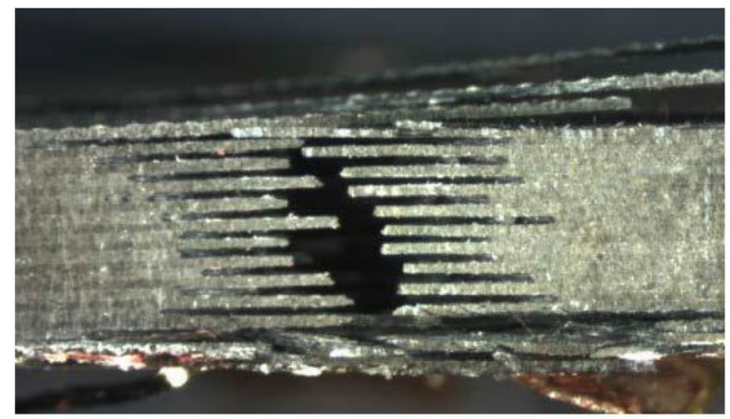

(d) side view of specimen featuring hole only

Fig. 5 Breadboard specimen failure modes

experiment and the resultant axial force in the simulation were equal. The stresses were transformed into the local (fiber oriented) coordinate system for each ply with $x_{1}$ as the ply's fiber direction. Subsequently, the stresses were plotted into the diagram of the failure envelope. Selected results for a specimen featuring both, hole and tapered section and tested at ambient temperature are presented in Fig. 6. In this context, the results along the hole (Fig. 3) are presented in Fig. $6 \mathrm{a}, \mathrm{b}$ for the $\left[+30^{\circ}\right]$ - and the $\left[-30^{\circ}\right]$-ply in the centre of the specimen, respectively. The same evaluation is performed in Fig. 6c, d, respectively, for the $\left[+30^{\circ}\right]$ - and the $\left[-30^{\circ}\right]$-ply along the tapered section. Similar results were obtained for all specimens tested. Full details on the experimental results and the numerical evaluation are given in the technical report on the project as well as in an oncoming contribution (Hohe et al. [7, 9]).

\section{Assessment of Puck's criterion}

According to Puck's criterion $[16,17]$, adopting the weakest link principle, a structure reaches a critical state once the stress state anywhere in the structure is located on the failure envelope in stress space. According to this concept, a critical state is reached for the specimen featuring hole and tapered section at the instant of evaluation according to Fig. 6 in the plies with a $\left[-30^{\circ}\right]-$ orientation of the fibers. Here the local stresses come close to the failure envelope, indicating that a critical state will be reached after a small further increase in the applied external load (and thus in the local stresses). In this context, first ply failure is predicted in the notch root of the hole (Fig. 6b), i.e., at the position, where the hole's surface is closest to the external specimen surface. All other locations feature stress states well within the failure envelope and, therefore, are judged to be uncritical according to the adopted criterion. However, a similar situation with only slightly lower stresses is obtained for the plies with the $\left[+30^{\circ}\right]$-orientation (Fig. 6a). The stresses in both plies are not equal due to the presence of the tapered section on one side of the hole, resulting in different loads along the fibers oriented in $\left[+30^{\circ}\right]$ - and $\left[-30^{\circ}\right]$-directions. A similar stress assessment in the biaxial plane of the failure envelope yields only situations with local stress points far from the failure envelope. These situations are judged as uncritical.

The failure prediction by Puck's failure criterion $[16,17]$ according to Fig. 6 is found in a rather good agreement with the experimental observation. Both, the instant of first ply failure (Fig. 4) and the location of failure initiation (Fig. 5) are predicted accurately. Since the maximum local stress did not finally reach the failure envelope at the load level, where first ply failure was observed experimentally, the instant of first ply failure in this case is predicted slightly late, i.e., after a further increase of external load and thus the local stresses. 


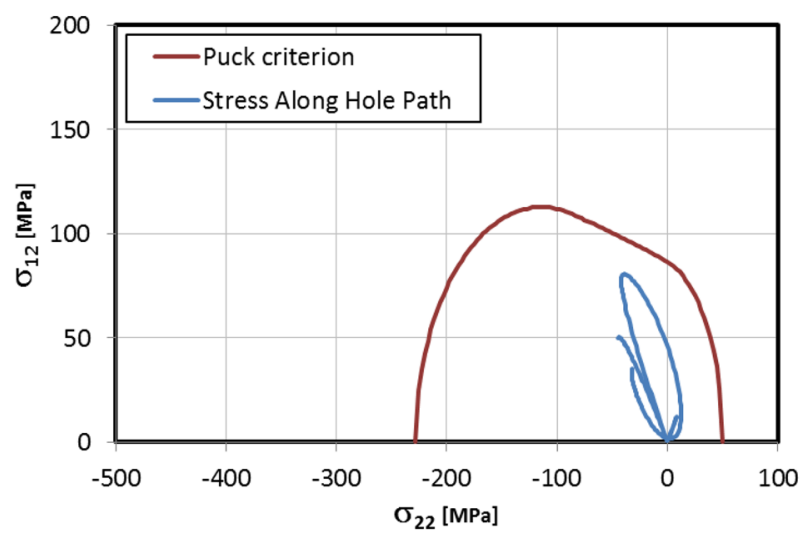

(a) hole, inter fiber plane, $+30^{\circ}$ ply

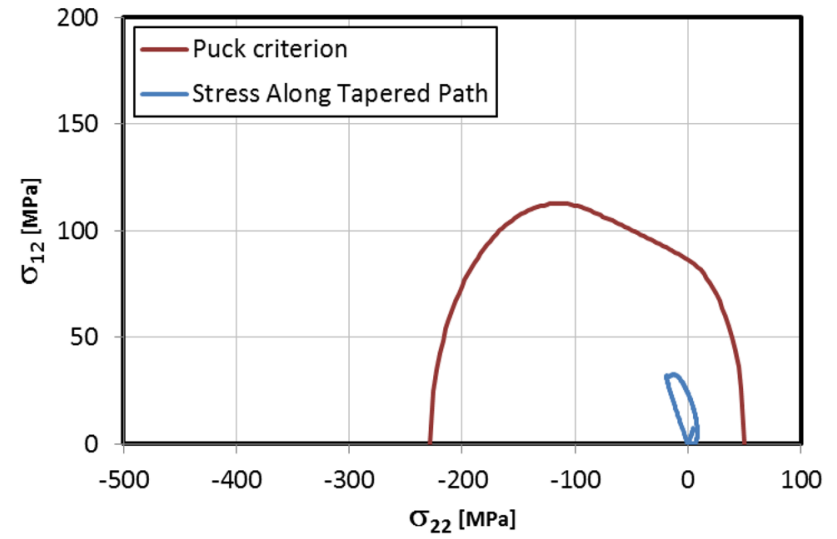

(c) tapered section, inter fiber plane, $+30^{\circ}$ ply

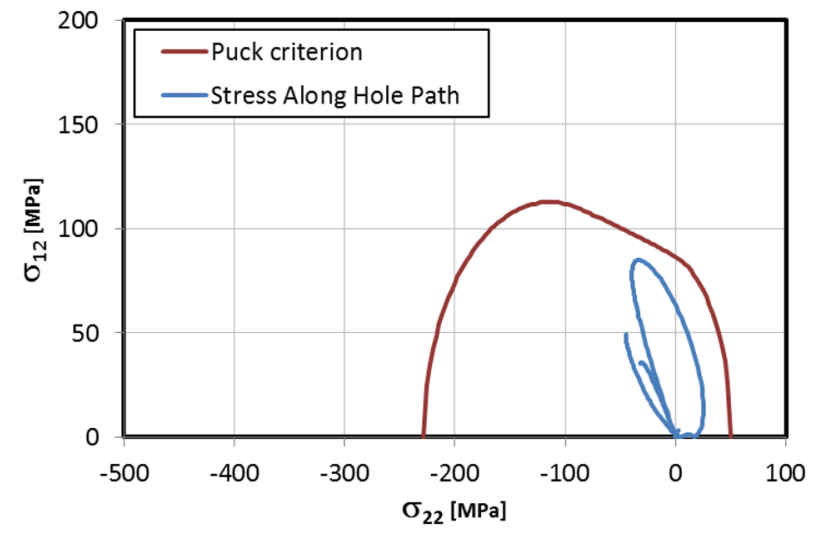

(b) hole, inter fiber plane, $-30^{\circ}$ ply

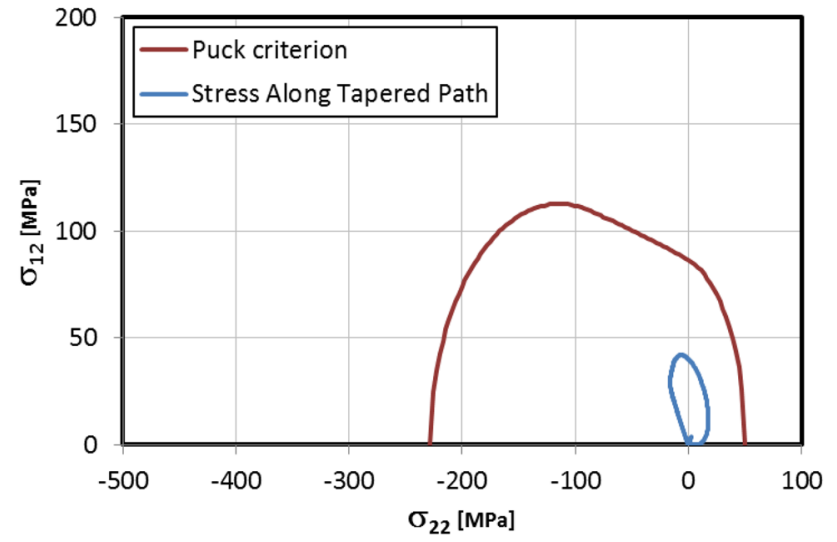

(d) tapered section, inter fiber plane, $-30^{\circ}$ ply

Fig. 6 Stresses along the features at first ply failure (specimen featuring both, hole and tapered section tested at ambient temperature)

Table 2 Failure load predictions compared to experimental observations

\begin{tabular}{llllll}
\hline Demonstrator type & \multicolumn{2}{l}{$296 \mathrm{~K}$} & & \multicolumn{2}{l}{$4 \mathrm{~K}$} \\
\cline { 2 - 3 } \cline { 5 - 6 } & \multicolumn{2}{l}{$F_{\text {failure }}^{\text {rel }}[\%]$} & & & \\
\cline { 2 - 5 } & Average & Std.-dev & Average & Std.-dev \\
\hline Hole only & 71.9 & 12.5 & $-*$ & -* $^{*}$ \\
Tapered section only & 66.4 & 8.7 & $-^{*}$ & -* $^{*}$ \\
Both features & 73.2 & 25.2 & & 96.7 & 54.3 \\
\hline
\end{tabular}

*No reliable results on first ply failure could have been determined

For the presented case, first ply failure is predicted at $116 \%$ of the experimentally observed first ply failure load level.

For all other experiments on the breadboard type specimens similar predictions of first ply failure were obtained. Computing the relative predicted failure load $F_{\text {failyre }}^{\text {rel }}=F_{\text {failure }}^{\text {pred }} / F_{\text {failure }}^{\text {exp }}$ as the ratio of the predicted load level $F_{\text {failure }}^{\text {pred }}$ for first ply failure to the experimentally observed load level $F_{\text {failure }}^{\exp }$ for first ply failure results in the values listed in Table 2 . For all cases, the averages and the standard deviations, respectively, out of three tests are presented. At ambient temperature, conservative predictions with limited scatter are obtained for all three demonstrator types. At cryogenic temperature, a reasonably conservative estimate is obtained for the demonstrator with both features. For the two other demonstrator types, however, it turned out to be rather difficult to identify the instants of first ply failure. Compared to the demonstrators tested at ambient temperature, the instant of first ply failure here had to be identified from the local strain measurements alone, since no visual observation was possible. Therefore, due to strain measurements superimposed by a considerable amount of white noise, no reliable determination of the instant of first ply failure was possible here.

\section{Summary and conclusion}

The present study is concerned with an assessment of the capability of Puck's failure criterion to predict failure of CFRP materials at ambient and cryogenic temperatures. For 
this purpose, an experimental study on IM7 carbon fiber composites with epoxy matrix has been performed. The experimental data base comprises of quasi-static tensile, compressive, shear and off-axis experiments at ambient temperature and in a liquid Helium environment.

In a first step, an experimental investigation was executed on coupon level, using standard tensile, compressive and shear experiments. The experiments were performed at $296 \mathrm{~K}$ and $4 \mathrm{~K}$. The results were utilized to determine the failure envelope according to Puck's criterion in stress space at both temperatures. In a second step, breadboard type specimens featuring holes and tapered sections to induce more general stress states were tested at the same temperatures. The experiments were simulated numerically and evaluated in terms of Puck's criterion using the aforementioned failure envelopes.

Validating the numerical predictions against the experimental data, Puck's criterion is found to provide a slightly conservative prediction of the instant for development of first ply failure. At this instant, first damage_-in most cases as inter fiber crack development-is triggered. However, in most cases no pronounced loss in the overall stiffness is observed. Thus no significant structural implication of the local damage event is indicated.

Regarding the effect of temperature on the strength limit, failure envelopes with different sizes but similar shapes were obtained for both temperatures. Thus, the criterion appears to be applicable at both temperatures, however, with temperature dependent parameters. Nevertheless, it should be pointed out that the changes in the failure envelopes due to temperature changes might result in a change of the failure mode to be expected at the considered material point and the actual stress state. Furthermore, it should be noticed that a local first ply failure in a specific mode may trigger total failure at this point in a different mode. In this context, inter fiber cracks with a limited size may act as triggers for delamination or fiber breakage at the respective material point due to local stress re-distribution and subsequent overloading, although at a first glance, other positions would be judged as more critical.

Based on the results of the present study, Puck's criterion can be considered to provide accurate predictions of failure on single ply level at both, $296 \mathrm{~K}$ and $4 \mathrm{~K}$. For intermediate temperatures, additional tests are necessary, since it has been shown in literature that different, partially opposing effects might govern the failure of FRP materials when cooling the material down into the cryogenic regime. The same holds for temperature variations beyond ambient temperature, although much less severe effects are expected here.

The main limitation of Puck's criterion is its restriction to first ply failure. The criterion assesses only the instant of the development of first damage. An assessment of a possible remaining load carrying capacity after the development of first cracks is not possible. In the breadboard experiments, a substantial residual load carrying capacity was obtained, since the complete fracture of the breadboard specimens with multi directional fiber reinforcement by inter fiber fracture alone is impossible. In addition, the delamination of large areas of the ply interfaces is required. Potential enhancements to circumvent these problems may consist in the application of continuum damage mechanics material models. By this means, a simulation of the progressive failure process and thus a direct assessment of the remaining load carrying capacity at all stages of failure would become possible. First approaches in this sense have already been provided in literature (e.g., Bogenfeld and Kreikemeier [2], Völkerink et al. [20]). Delamination between neighboring plies might be included into the modelling, e.g., by means of cohesive zones between the relevant plies.

Acknowledgements The present paper provides an expanded version of a contribution presented at the 1st Aerospace Europe Conference (Bordeaux, February 25 to 28,2020 [8]).

Funding Open Access funding provided by Projekt DEAL. The work has been funded by the European Space Agency ESA under contract no. 4000118053/16/NL/BJ.

Availability of data and material The data and the material form part of an ongoing activity and thus cannot be shared at the time.

Code availability The finite element analyses have been performed by means of the ABAQUS program. For all other computations and evaluations, in-house codes and procedures have been employed.

\section{Compliance with ethical standards}

Conflict of interest The authors declare that they have no known competing financial interests or personal relationships that could have appeared to influence the work reported in this paper.

Open Access This article is licensed under a Creative Commons Attribution 4.0 International License, which permits use, sharing, adaptation, distribution and reproduction in any medium or format, as long as you give appropriate credit to the original author(s) and the source, provide a link to the Creative Commons licence, and indicate if changes were made. The images or other third party material in this article are included in the article's Creative Commons licence, unless indicated otherwise in a credit line to the material. If material is not included in the article's Creative Commons licence and your intended use is not permitted by statutory regulation or exceeds the permitted use, you will need to obtain permission directly from the copyright holder. To view a copy of this licence, visit http://creativecommons.org/licenses/by/4.0/.

\section{References}

1. ABAQUS 2018: User's manual. Dassault Systemes SIMULIA Corp., Johnston, RI (2018). 
2. Bogenfeld, R., Kreikemeier, J.: A tensorial based progressive damage model for fiber reinforced polymers. Compos. Struct. 168, 608-618 (2017)

3. Dávila, C.G., Camanho, P.P., Rose, C.A.: Failure criteria for FRP laminates. J. Compos. Mat. 39, 323-345 (2005)

4. Hashin, Z., Rotem, A.: A fatigue failure criterion for fiber reinforced materials. J. Compos. Mat. 7, 448-464 (1973)

5. Hashin, Z.: Failure criteria for unidirectional fiber composites. J. Appl. Mech. 47, 329-334 (1980)

6. Hohe, J., Fliegener, S., Weiss, K.P., Appel, S.: Verification of failure criteria for FRP composites under cryogenic thermo-mechanical loading. 15th Europ. Conf. Spacecraft Structures, Materials and Environmental Testing (Noordwijk, May 28 to June 01, 2018).

7. Hohe, J., Schober, M., Fliegener, S., Weiss, K.P.: Verification of composite laminates under cryogenic thermo-mechanical loading, Report No. V1208/2019, Fraunhofer Institute for Mechanics of Materials IWM, Freiburg 2019.

8. Hohe, J., Schober, M., Weiss, K.P., Appel, S.: Failure criteria for CFRP composites in the cryogenic regime. 1st Aerospace Europe Conf. (Bordeaux, February 25 to 28, 2020).

9. Hohe, J., Schober, M., Weiss, K.P., Appel, S.: Verification of Puck's criterion for CFRP laminates under multiaxial loads at ambient and cryogenic temperatures. Submitted.

10. Hui, D., Dutta, P.K.: Cryogenic temperature effects on performance of polymer composites, Proc. 5th Conf. Aerospace Materials, Processes and Environmental Technology (Huntsville, AL, September 16-18, 2002).

11. Hyer, M.W., Cooper, D.E., Cohen, D.: Stresses and deformation in cross-ply composite tubes subjected to a uniform temperature change. J. Thermal Stresses 9, 97-117 (1986)

12. Kumagai, S., Shindo, Y.: Experimental and analytical evaluation of the notched tensile fracture of CFRP woven laminates at low temperatures. J. Compos. Mat. 38, 1151-1164 (2004)

13. Lord, H.W., Dutta, P.K.: On the design of polymeric composite structures for cold regions application. J. Reinf. Plastics Compos. 7, 435-458 (1988)
14. Meng, J., Wang, Y., Yang, H., Wang, P., Lei, Q., Shi, H., Lei, H., Fang, D.: Mechanical properties and internal microdefects evolution of carbon fiber reinforced polymer composites: cryogenic temperature and thermocycling effects. Compos. Sci. Tech. 191, 108083 (2020)

15. Pinho, S.T., Iannucci, L., Robinson, P.: Physically-based failure models and criteria for laminated fibre-reinforced composites with emphasis on fibre kinking: Part I: Development. Compos. A 37, 63-73 (2006)

16. Puck, A., Schürmann, H.: Failure analysis of FRP laminates by means of physically based phenomenological models. Compos. Sci. Tech. 58, 1045-1067 (1998)

17. Puck, A., Schürmann, H.: Failure analysis of FRP laminates by means of physically based phenomenological models. Compos. Sci. Tech. 62, 1633-1662 (2002)

18. Shokrieh, M.M., Torabizadeh, M.A., Fereidoon, A.: Progressive failure analysis of glass/epoxy composites at low temperatures. Strength Mat. 44, 314-324 (2012)

19. Tsai, S.P., Wu, E.M.: A general theory of strength for anisotropic materials. J. Compos. Mat. 5, 58-80 (1971)

20. Völkerink, O., Petersen, E., Koord, J., Hühne, C.: A pragmatic approach for a 3D material model considering elasto-plastic behaviour, damage initiation by Puck or Cuntze and progressive failure of fibre-reinforced plastics. Comput. Struct. 236, 106280 (2020)

Publisher's Note Springer Nature remains neutral with regard to jurisdictional claims in published maps and institutional affiliations. 